\title{
Bending and shear behavior of ultra-high performance fiber reinforced concrete
}

\author{
C. Magureanu, I. Sosa, C. Negrutiu \& B. Heghes \\ Reinforced Concrete and Steel Structures Department, \\ Technical University of Cluj-Napoca, Romania
}

\begin{abstract}
This paper presents the experimental research regarding the physical-mechanical properties and the bending and shear behavior of the ultra high performance concrete. The cementitious composite with $2 \%$ volume of steel fibers was tested for the following characteristics: the compressive and tensile strength, the stressstrain characteristic curve for compression strength and flexural strength. Furthermore, a series of reinforced elements were tested and analyzed in terms of maximum crack width, deformations and maximum compressive strain. The specimens subject to $90^{\circ} \mathrm{C}$ thermal treatment for 5 days displayed an increase of compressive strength up to $180 \mathrm{MPa}$ at the age of 6 days. The experimental data obtained on specimens with a thermal curing regime are evaluated by comparison with specimens with a water-curing regime.
\end{abstract}

Keywords: ultra high performance concrete, compression, tension, splitting, flexure, shear, bending, fiber.

\section{Introduction}

Ultra high performance fiber reinforced concrete (UHPFRC) stands for concretes with compressive strengths exceeding $150 \mathrm{MPa}$ [1]. The concrete composition includes high cement content, mineral admixture (usually silica fume), steel fibers and a very low water/binder ratio, ensured by the use of last generation superplasticizers [1-4]. UHPFRC incorporates very fine sands or quartz sands with granule size up to $1 \mathrm{~mm}$. Besides the superior physical-mechanical properties compared with ordinary concrete and even high strength concrete, UHPFRC presents very good ductility and durability properties [1-6]. 


\section{Mechanical properties}

\subsection{Experimental program}

The experimental program comprised the study of the mechanical properties of ultra-high performance with fibers (UHPFRC) and without fibers (UHPC). Both mixtures used Portland cement type CEM I 52.5R, gray silica fume and very fine sand with granulometry of $0-0.3 \mathrm{~mm}$ and $0.4-1.2 \mathrm{~mm}$. The coarse aggregates were eliminated. The flowability of the concrete was insured by the polymer ether-carboxylate superplasticizers. The composition of the two concretes is presented in Table 1.

Two curing regimes were applied for specimens used for mechanical properties determinations:

- thermal treatment for 5 days with a constant temperature of $90^{\circ} \mathrm{C}$.

- water curing for 5 days with a constant temperature of $20 \pm 2^{\circ} \mathrm{C}$.

Subsequently, the specimens were kept in the laboratory environment (temperature $20 \pm 2{ }^{\circ} \mathrm{C}$ and relative humidity $60 \pm 5 \%$ ) until testing.

The strength and deformability characteristics were determined with a digital hydraulic testing machine with deformation control, type ADVANTEST 9. The displacements were measured using LVDTs. A general view of the testing machine is displayed in Figure 1.

Table 1: Concrete composition.

\begin{tabular}{|c|c|c|}
\hline Materials & UHPC & UHPFRC \\
\hline Cement CEM 52.5R & 1.00 & 1.00 \\
\hline Water/cement ratio $(\mathrm{w} / \mathrm{c})$ & 0.174 & 0.174 \\
\hline Water/binder ratio $(\mathrm{w} / \mathrm{b})$ & 0.138 & 0.138 \\
\hline Sand $(0-0.3)+(0.4-1.2 \mathrm{~mm})$ & 1.18 & 1.18 \\
\hline Silica fume & 0.26 & 0.26 \\
\hline Superplasticizers & 0.0305 & 0.0305 \\
\hline Steel fibers & 0 & 0.174 \\
\hline
\end{tabular}

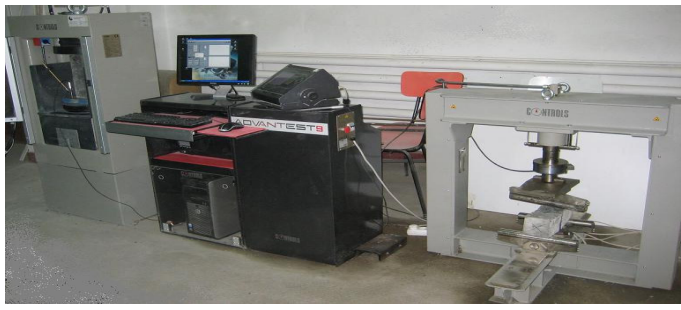

Figure 1: Mechanical properties testing machine. 


\subsection{Fresh concrete properties}

The flowability of the concrete was investigated with the slump flow test conducted immediately after the mixing process ended. It was observed that the steel fibers incorporation does not have a major influence on the concrete flowability, the slump flow measurement being about $120 \mathrm{~mm}$.

The water/cement ratio was 0.174 . All specimens were produced from the same batch in order to eliminate the influence of the mixing condition.

The specimens had the following geometry: 70x70x70mm and 100x100x100 $\mathrm{mm}$ cubes, $40 \times 40 \times 160 \mathrm{~mm}$ and $100 \times 100 \times 300 \mathrm{~mm}$ prisms.

The specimens were demolded $24 \mathrm{~h}$ after casting.

\subsection{Compressive and splitting tensile strength}

The compressive strength (fc) was measured on $70 \times 70 \times 70 \mathrm{~mm}$ cubes. The splitting tensile strength (fct,sp) was measured on $100 \times 100 \times 100 \mathrm{~mm}$ cubes. The testing ages were 6,14 and 28 days for both $(\mathrm{T})$, thermal treatment $\left(5\right.$ days, $\left.90^{\circ} \mathrm{C}\right)$ and (W), water curing regime ( 5 days, water, temperature $20 \pm 2^{\circ} \mathrm{C}$ ). The results are listed in Table 2 for the compressive strength and in Table 3 for the splitting tensile strength.

The compressive strength of thermal treated specimens is about $15 \%$ higher for UHPFRC compared to UHPC.

It can be observed an increase of about $220 \%$ of the splitting tensile strength of UHPFRC compared with UHPC for the thermal treated specimens.

\subsection{Flexural strength}

The flexural strength was investigated by performing a 3 point bending test using

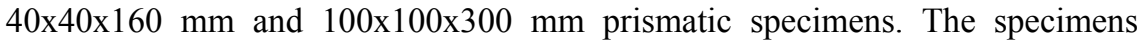
were thermal treated $(\mathrm{T})$.

Table 2: Compressive strength.

\begin{tabular}{|c|c|c|c|c|c|c|}
\hline \multirow{3}{*}{$\begin{array}{c}\begin{array}{c}\text { Specimen } \\
\text { geometry }\end{array} \\
{[\mathrm{mm}]}\end{array}$} & \multirow{3}{*}{ 密 } & \multirow{3}{*}{. } & Mechanical & \multicolumn{3}{|c|}{ Concrete Age } \\
\hline & & & properties & 6 & 14 & 28 \\
\hline & & & [MPa] & \multicolumn{3}{|c|}{ days } \\
\hline $\begin{array}{c}\text { Cube } \\
70 \times 70 \times 70\end{array}$ & 2 & $\mathrm{~T}$ & $f_{c}$ & 160.2 & 160.4 & 167.5 \\
\hline $\begin{array}{c}\text { Cube } \\
70 \times 70 \times 70\end{array}$ & 5 & W & $f_{c}$ & 107.7 & 116.2 & 102.9 \\
\hline $\begin{array}{c}\text { Cube } \\
70 \times 70 \times 70\end{array}$ & 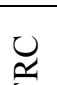 & $\mathrm{T}$ & $f_{c}$ & 181.3 & 185.5 & 181.2 \\
\hline $\begin{array}{c}\text { Cube } \\
70 \times 70 \times 70\end{array}$ & 志 & W & $f_{c}$ & 130.5 & 128.8 & 138.2 \\
\hline
\end{tabular}


82 High Performance Structures and Materials V

Table 3: $\quad$ Splitting tensile strength.

\begin{tabular}{|c|c|c|c|c|c|c|}
\hline \multirow{3}{*}{$\begin{array}{c}\text { Specimen } \\
\text { geometry } \\
{[\mathrm{mm}]}\end{array}$} & \multirow{3}{*}{ 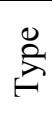 } & \multirow{3}{*}{ 先 } & Mechanical properties & \multicolumn{3}{|c|}{ Concrete Age } \\
\hline & & & & 6 & 14 & 28 \\
\hline & & & {$[\mathrm{MPa}]$} & \multicolumn{3}{|c|}{ days } \\
\hline Cube $100 \times 100 \times 100$ & 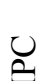 & $\mathrm{T}$ & $\mathrm{f}_{\mathrm{ct}, \mathrm{sp}}$ & 7.9 & 9.2 & 9.4 \\
\hline Cube $100 \times 100 \times 100$ & $\stackrel{\mathbb{D}}{\square}$ & W & $f_{\text {ct.sp }}$ & 5.8 & 7.7 & 6.9 \\
\hline Cube $100 \times 100 \times 100$ & $\underset{\sim}{\mathscr{I}}$ & $\mathrm{T}$ & $f_{\text {ctsp }}$ & 17.5 & 20.2 & 20.4 \\
\hline Cube $100 \times 100 \times 100$ & 焉 & W & $\mathrm{f}_{\mathrm{ct}, \mathrm{sp}}$ & 6.6 & 7.8 & 12.6 \\
\hline
\end{tabular}

Table 4: $\quad$ Flexural strength.

\begin{tabular}{|c|c|c|c|c|c|c|}
\hline \multirow{2}{*}{$\begin{array}{l}\text { Specimen } \\
\text { geometry }\end{array}$} & \multirow{3}{*}{ 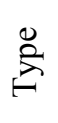 } & \multirow{3}{*}{ 罵 } & Mechanical & \multicolumn{3}{|c|}{ Concrete Age } \\
\hline & & & properties & 6 & 14 & 28 \\
\hline$[\mathrm{mm}]$ & & & {$[\mathrm{MPa}]$} & \multicolumn{3}{|c|}{ days } \\
\hline Prism 40x40x160 & $\bigcup_{2}$ & $\mathrm{~T}$ & $\mathrm{f}_{\mathrm{ct}, \mathrm{fl}}$ & 13.4 & 13.8 & 14.8 \\
\hline $\begin{array}{c}\text { Prism } \\
100 \times 100 \times 300\end{array}$ & $\stackrel{\Xi}{\square}$ & $\mathrm{T}$ & $\mathrm{f}_{\mathrm{ct}, \mathrm{fl}}$ & 6.05 & 6.78 & 7.02 \\
\hline Prism 40x40x160 & $\frac{\widetilde{r}}{\tau}$ & $\mathrm{T}$ & $\mathrm{f}_{\mathrm{ct}, \mathrm{fl}}$ & 21.8 & 23.1 & 22.30 \\
\hline $\begin{array}{c}\text { Prism } \\
100 \times 100 \times 300\end{array}$ & 量 & $\mathrm{T}$ & $\mathrm{f}_{\mathrm{ct}, \mathrm{fl}}$ & 11.5 & 12.7 & 16.6 \\
\hline
\end{tabular}

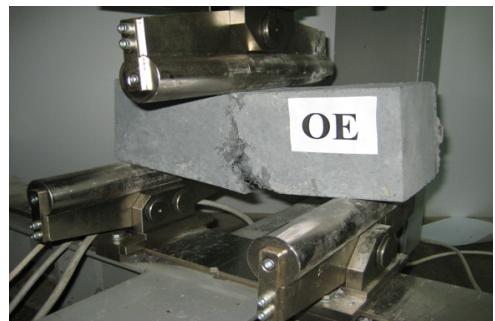

(a)

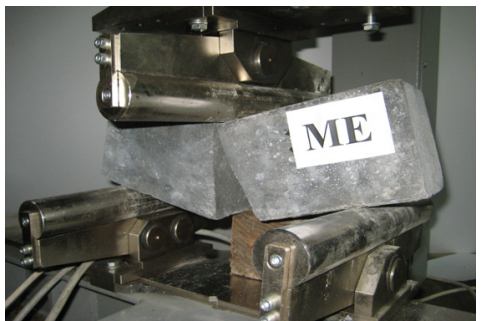

(b)

Figure 2: (a) Flexure failure of UHPFRC; (b) flexure failure of UHPC.

The testing procedures using ADVANTEST9 testing machine and the failure of the specimens are illustrated in Figure 2.

Fiber reinforced concrete (UHPFRC) showed a flexural strength 150-165\% higher than un-reinforced concrete (UHPC). The geometry of the specimens influenced the flexural strength, smaller specimens exhibiting a higher strength, as seen in Table 4 . 


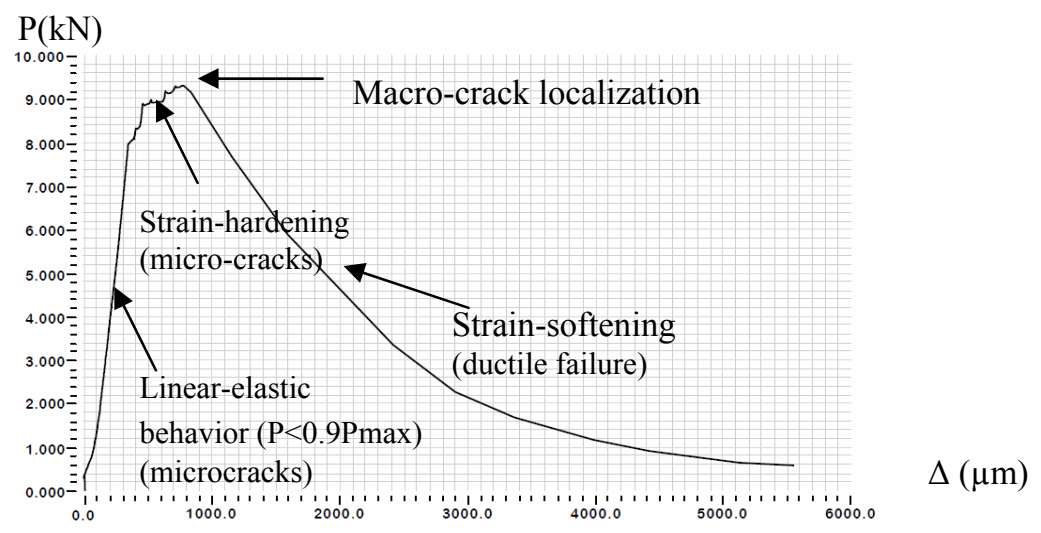

Figure 3: $\quad$ Load $\mathrm{P}(\mathrm{kN})$ vs. mid span deflection $\Delta(\mu \mathrm{m})$ curve (UHPFRC).

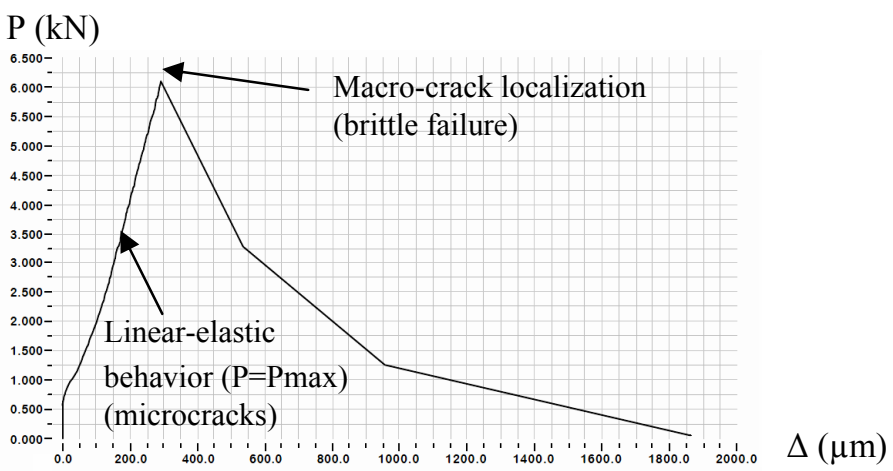

Figure 4: $\quad$ Load $\mathrm{P}(\mathrm{kN})$ vs. mid span deflection $\Delta(\mu \mathrm{m})$ curve (UHPC).

The flexural behavior of the two types of concrete can be observed by analyzing the load-deflection curves in Figures 3 and 4. UHPFRC displayed a ductile behavior.

The middle span deflection at maximum load, as well as the ultimate middle span deflection, is about three times higher for UHPFRC compared to UHPC (900 $\mu \mathrm{m}$ compared to $300 \mu \mathrm{m})$. The peak load of UHPFRC was 1.5 times higher than the peak load of UHPC.

\section{Bending and shear behavior of UHPC beams}

\subsection{Experimental program}

The bending and shear behavior was tested on four I-shaped beams with identical cross sections. 
The bending beams had a total length of $3.2 \mathrm{~m}$ with a span of $3 \mathrm{~mm}$. The shear beams had a total length of $1.67 \mathrm{~m}$ and a span of $1.5 \mathrm{~m}$. The beams are described in Table 5.

Beams' reinforcement and geometry are described in Figures 5, 6, 7, and 8 .

The beams were demolded after $24 \mathrm{~h}$ and afterwards were subject to thermal treatment for 5 days with a constant temperature of $90^{\circ} \mathrm{C}$ and a relative humidity of $40 \%$.

Table 5: $\quad$ Beam description.

\begin{tabular}{|l|l|l|}
\hline Beam types & \multicolumn{2}{|c|}{ Load } \\
\hline & Bending & Shear \\
\hline Without fibers & TS1 & TS2 \\
\hline With fibers & TSF1 & TSF2 \\
\hline
\end{tabular}

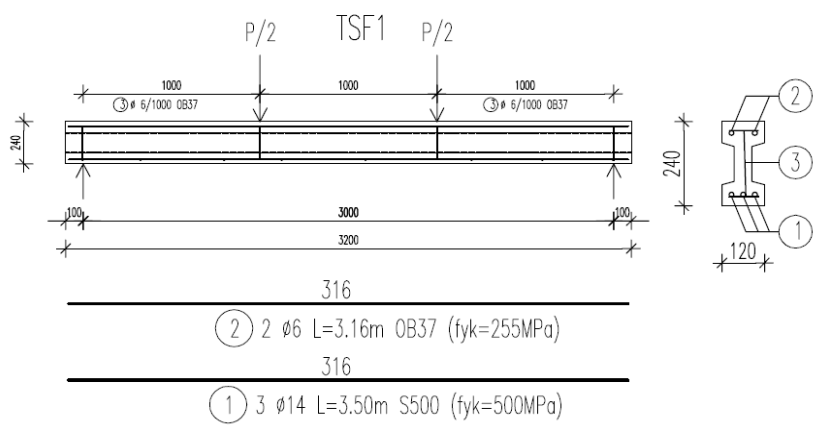

Figure 5: TSF1 reinforcement and geometry.

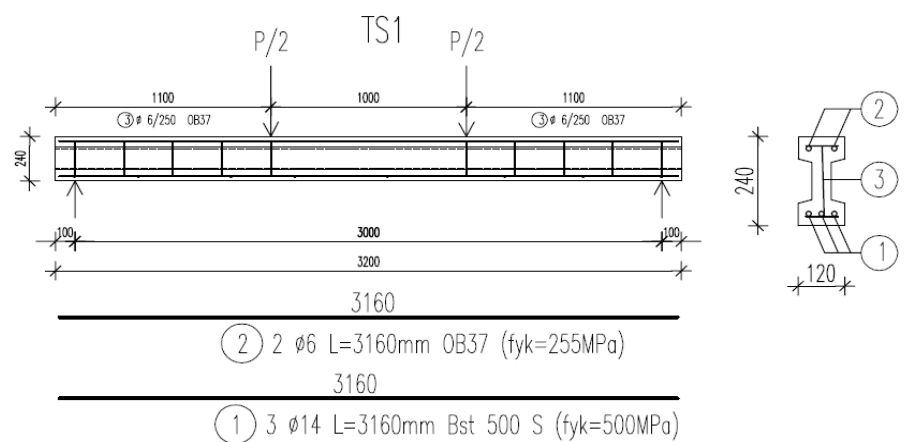

Figure 6: TS1 reinforcement and geometry. 


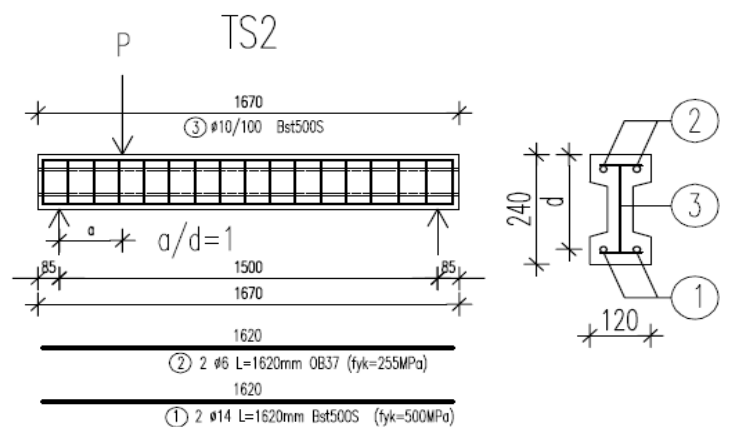

Figure 7: $\quad$ TS2 reinforcement and geometry.

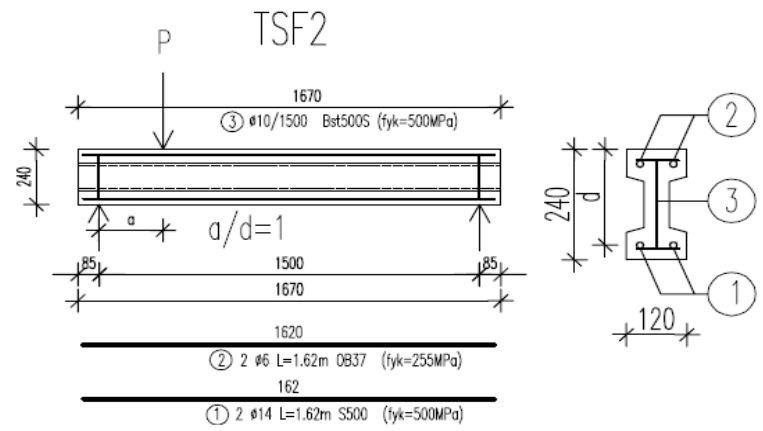

Figure 8: $\quad$ TSF2 reinforcement and geometry.

\subsection{Testing procedure}

The beams' age was 28 days when tested. Tested beams' measurement included: -displacements measured in 5 sections for bending and 3 sections for shear with $0.1 \mathrm{~mm}$ precision;

-middle span displacement with transducers with $0.03 \mathrm{~mm}$ precision -cracks width by $0.1 \mathrm{~mm}$ precision apparatus -cracks distance

Aspects regarding test setups are displayed in Figure 9.

\subsection{Tests results}

\subsubsection{Bending}

The results are plotted in Table 6 and the following observations can be made:

a) Bending beam with re-bars only: -maximum crack width $\mathrm{W}_{\text {cr }}^{\mathrm{max}}=0.1 \mathrm{~mm}$ -maximum displacement for the serviceability limit state (1/250) was recorded for $\mathrm{M} / \mathrm{Mu}=0.57$

b) Bending beam with re-bars and steel fibers: -maximum crack width $\mathrm{W}_{\text {cr }}^{\mathrm{max}}=0.1 \mathrm{~mm}$ 
-maximum displacement for the serviceability limit state $(1 / 250)$ was recorded for $\mathrm{M} / \mathrm{Mu}=0.46$

The bending moments ratio of the two beams for a crack width $\mathrm{W}_{\mathrm{cr}} \max ^{\max }=0.1 \mathrm{~mm}$ is $\mathrm{M}^{\mathrm{TS}}{ }_{0.1} / \mathrm{M}^{\mathrm{TSF} 1}=0.1=62$. The fiber addition almost doubles the maximum bending moment, as expressed by the moment ratio of the two beams $\mathrm{M}_{0.1}^{\mathrm{TS} 1}$ $\mathrm{M}_{0.1}^{\mathrm{TSF} 1}=1.87$.

The ultimate strain in compression for the beam with fiber addition is 3.14 times higher than that of the beam without fibers.

Load-mid span displacement curves can be analyzed in Figure 10.

The failure of the beams is presented in Figure 11.

\subsubsection{Shear}

Tests results are plotted in Table 7. A maximum inclined crack of $0.1 \mathrm{~mm}$ is produced for a load ratio $\mathrm{P} / \mathrm{P}_{\mathrm{u}}=0.2$ in the stirrups reinforced beam $(1$ leg

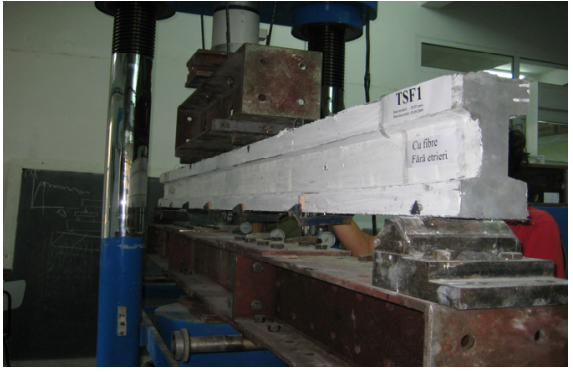

(a)

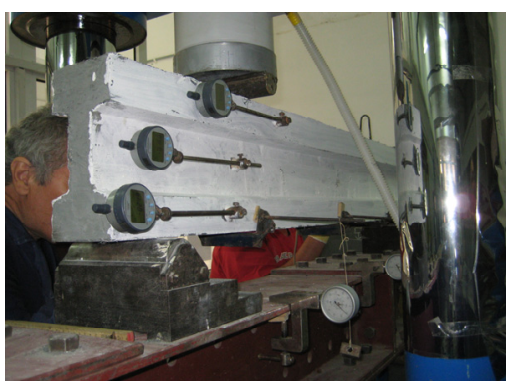

(b)

Figure 9: (a) Bending setup test; (b) shear setup test.

Table 6: Bending tests results.

\begin{tabular}{|c|c|c|c|c|c|c|}
\hline \multirow{2}{*}{ Beam } & $\mathrm{M}$ & $\mathrm{M} / \mathrm{Mu}$ & $\mathrm{W}_{\mathrm{cr}}^{\max }$ & $\Delta$ & $\varepsilon_{\mathrm{c}}^{\max }$ & \multirow{2}{*}{ Notes } \\
\hline & $\mathrm{kNm}$ & & {$[\mathrm{mm}]$} & {$[\mathrm{mm}]$} & {$\left[\% \%_{0}\right]$} & \\
\hline \multirow{4}{*}{$\begin{array}{c}\text { TS1 } \\
\text { no } \\
\text { fibers }\end{array}$} & 10 & 0.57 & 0.1 & $7.9(1 / 250)$ & 0.75 & \multirow{9}{*}{$\begin{array}{l}\text { M=bending } \\
\text { moment } \\
\text { Mu=maximum } \\
\text { bending moment } \\
\mathrm{W}_{\mathrm{cr}}^{\text {max }}=\text { maximum } \\
\text { crack width } \\
\Delta=\text { middle span } \\
\text { displacement } \\
\varepsilon_{\mathrm{c}}{ }^{\text {max }}=\text { ultimate } \\
\text { strain } \\
\text { (compression) } \\
l=\text { beam span }\end{array}$} \\
\hline & 12.5 & 0.71 & 0.2 & $8.2(1 / 190)$ & 1.05 & \\
\hline & 15 & 0.86 & 0.5 & $12.5(1 / 160)$ & 1.50 & \\
\hline & 17.5 & 1.00 & - & $14.5(1 / 70)$ & 1.75 & \\
\hline \multirow{5}{*}{$\begin{array}{l}\text { TSF1 } \\
\text { with } \\
\text { fibers }\end{array}$} & 13.7 & 0.39 & 0.05 & $9(1 / 333)$ & 0.87 & \\
\hline & 16.1 & 0.49 & 0.1 & $15.2(1 / 200)$ & 1.05 & \\
\hline & 23 & 0.70 & 0.2 & $22.1(1 / 135)$ & 1.50 & \\
\hline & 27.5 & 0.87 & 0.3 & $26.8(1 / 111)$ & 2.05 & \\
\hline & 32.73 & 1.00 & - & $71.0(1 / 42)$ & 5.50 & \\
\hline
\end{tabular}




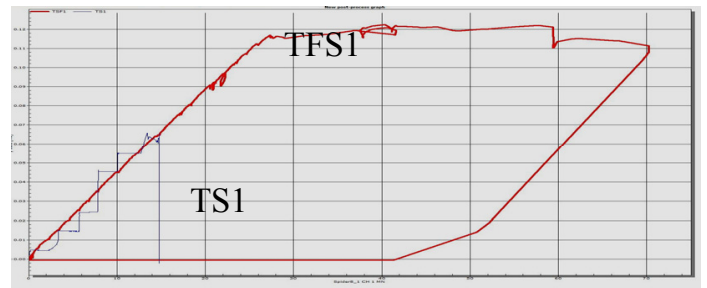

Figure 10: Load-mid span deflection, bending testing.

Table 7: $\quad$ Shear tests results.

\begin{tabular}{|c|c|c|c|c|}
\hline \multirow{2}{*}{ Beam } & $\mathrm{P}$ & $\mathrm{P} / \mathrm{Pu}$ & $\mathrm{W}_{\mathrm{cr}}^{\max }$ & \multirow{2}{*}{ Notes } \\
\hline & $\mathrm{kN}$ & & {$[\mathrm{mm}]$} & \\
\hline \multirow{5}{*}{$\begin{array}{c}\text { TS2 } \\
\text { no } \\
\text { fibers }\end{array}$} & 25.00 & 0.20 & 0.1 & \multirow{10}{*}{$\begin{array}{l}\mathrm{P}=\text { force } \\
\mathrm{Pmax}=\text { maximum force } \\
\mathrm{W}_{\mathrm{cr}} \max _{\text {r }}=\text { maximum inclined crack } \\
\text { width } \\
\mathrm{a} / \mathrm{d}=1 \text { (shear slenderness ratio) } \\
\mathrm{P}^{\mathrm{F}}{ }_{0,1} / \mathrm{P}^{\mathrm{FF}}{ }_{0,1}=3.2 \\
\mathrm{P}_{\mathrm{u}}^{\mathrm{F}} / \mathrm{P}^{\mathrm{FF}}{ }_{\mathrm{u}}=2.04\end{array}$} \\
\hline & 39.00 & 0.32 & 0.2 & \\
\hline & 55.00 & 0.45 & 0.3 & \\
\hline & 60.00 & 0.49 & 0.4 & \\
\hline & 122.40 & 1.00 & - & \\
\hline \multirow{5}{*}{$\begin{array}{l}\text { TSF2 } \\
\text { with } \\
\text { fibers }\end{array}$} & 80.00 & 0.32 & 0.1 & \\
\hline & 142.00 & 0.56 & 0.2 & \\
\hline & 178.00 & 0.71 & 0.3 & \\
\hline & 188.00 & 0.75 & 0.5 & \\
\hline & 250.00 & 1.00 & - & \\
\hline
\end{tabular}

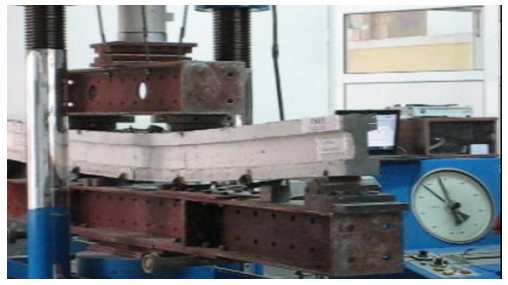

(a)

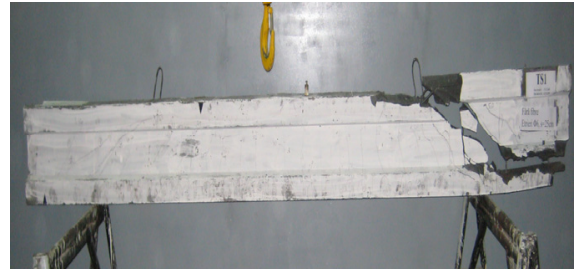

(b)

Figure 11: $\quad$ (a) Failure of TSF1; (b) failure of TS1

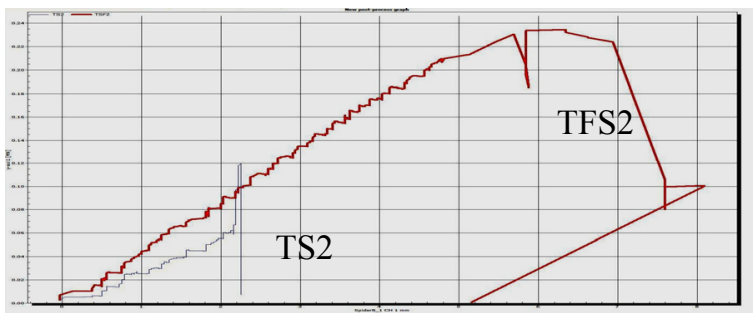

Figure 12: $\quad$ Load-mid span deflection, shear testing. 


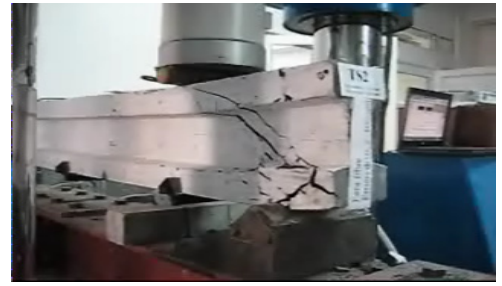

(a)

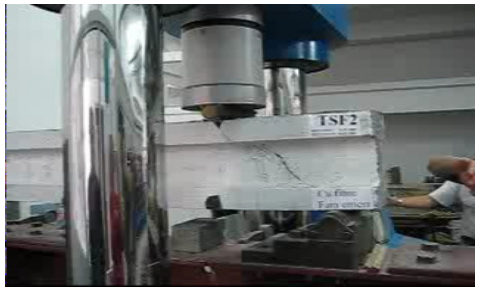

(b)

Figure 13: (a) Failure of TS2; (b) failure of TSF2.

$\emptyset 10 \mathrm{~mm}, \mathrm{~s}=100 \mathrm{~mm}$, steel Bst500S). The same crack opening of $0.1 \mathrm{~mm}$ is produced at $\mathrm{P} / \mathrm{P}_{\mathrm{u}}=0.32$ for the steel fiber reinforced beam (without stirrups). By adding fiber in concrete composition the rupture force is 2.04 times higher than for concrete without fibers.

Load-mid span deflection curves are displayed in Figure 12.

The failure of the beams is presented in Figure 13.

\section{Conclusions}

The paper presents the mechanical properties of ultra high performance concrete.

The influence of steel fiber reinforcement, age, geometry of the specimens and environmental conditions was evaluated.

Fiber reinforcement influence was analyzed in terms of mechanical properties and behavior of concrete beams in shear and bending. Thermal treatment improved mechanical strengths. Fiber addition improved the compressive strengths, but the most significant influence was on the tensile strengths and on the element behavior.

Smaller specimens exhibited higher flexural strength.

Splitting tensile strength of UHPFRC is about 2.2 times higher than that of UHPC.

It was observed a ductile post peak behavior for UHPFRC with $2 \%$ steel fibers by concrete volume.

For about $85-95 \%$ of the peak load, UHPC and UHPFRC displayed a quasilinear behavior when tested in flexure.

Regarding shear and bending tests on beams, the steel fibers addition improved the behavior and loading capacity for the tested beams.

The tests suggested that fiber reinforcement is extremely efficient and can successfully replace steel stirrups. This aspect is very important for both time and money saving. Moreover, ultra high performance concrete requires small cross sections and, bearing in mind the compressive strength of this concrete, it is quite impossible to use only stirrups as shear reinforcement.

\section{Acknowledgements}

This research was conducted within a PCE-PN II-IDEI Program, code 1053/2007, financed by National Scientific Research Council for Higher 
Education (CNCSIS), Romania. The authors would like to express their gratitude to CNCSIS.

\section{References}

[1] Rossi P. (2001) Ultra-High-Performance Fiber-Reinforced Concrete-A French Perspective on approaches used to produce high-strength, ductile fiber reinforced concrete, Concrete International, December, 46-52

[2] Magureanu C., Sosa I. (2008) Ultra High Performance Concrete. Reinforced and Prestressed concrete Structures Roads. Bridges and railways. Proceedings of the International Conference: Construction 2008, ClujNapoca. 127-132.

[3] Magureanu C., Heghes B., Corbu O, Szilagy H., Sosa I. (2008) Behavior of High and Ultra High Fiber Reinforced Concrete. 8th International Symposium on Utilization of High-Strength and High-Performance Concrete, Tokyo. 353-356.

[4] Magureanu C., Heghes B., Negrutiu C. (2009) Ultra High Performance Concrete with and without steel fiber. Concrete 21 Century Super Hero, London.

[5] Benjamin A. Graybeal, (2007) Compressive behavior of Ultra High Performance Fiber-Reinforced Concrete. ACI Materials Journal, MarchApril, 316-319.

[6] Sugamata T., Sugiyama T, Okazawa S. (2002) Study on the fresh and hardened properties of concrete containing superplasticizers for Ultra High Strength Concrete, Proceedings of the $1^{\text {st }}$ fib Congress, Session 9, 87-96. 